\title{
Incidence and diagnosis of ventilator-associated tracheobronchitis in the intensive care unit: an international online survey
}

\author{
Alejandro Rodríguez ${ }^{1}$, Pedro Póvoa ${ }^{2}$, Saad Nseir ${ }^{3}$, Jorge Salluh ${ }^{4}$, Daniel Curcio ${ }^{5}$, Ignacio Martín-Loeches ${ }^{6 *}$ \\ and on behalf of The TAVeM group investigators
}

\begin{abstract}
Introduction: Several aspects of ventilator-associated tracheobronchitis (VAT)—including diagnostic criteria, overlap with ventilator-associated pneumonia (VAP), and appropriate treatment regimens-remain poorly defined. The objectives of this study were to survey reported practices in the clinical and microbiological diagnosis of VAT and to evaluate perceptions of the impact of VAT on patient outcomes.

Methods: We developed a questionnaire consisting of (a) characteristics of the respondent, the ICU, and hospital; (b) current clinical and microbiological diagnostic approach; (c) empirical antibiotic therapy; and (d) the perception of physicians regarding the clinical impact of VAT and its implications.

Results: A total of 288 ICUs from 16 different countries answered the survey: 147 (51\%) from the Latin American (LA) group and 141 (49\%) from Spain, Portugal, and France (SPF group). The majority of respondents ( $\mathrm{n}=228$; 79.2\%) reported making the diagnosis of VAT based on clinical and microbiological criteria, and 40 (13.9\%) by clinical criteria alone. Approximately half (50.3\%) of the respondents agreed that patients should receive antibiotics for the treatment of VAT. Out of all respondents, 269 (93.4\%) assume that a VAT episode increases ICU length of stay, and this perception is greater in the LA group (97.3\%) than in the SPF group $(89.4 \%, P<0.05)$. Half of the physicians considered that VAT increases the risk of mortality, and this perception is again greater in the LA group $(58.5 \%$ versus $41.1 \%, P<0.05)$.

Conclusions: Given the possible high incidence of VAT and the perception of its importance as a risk factor for VAP and mortality, a large multicenter international prospective study would be helpful to validate a consensual definition of VAT, determine its incidence, and delineate its impact on subsequent VAP occurrence.
\end{abstract}

\section{Introduction}

Although mechanical ventilation (MV) is potentially lifesaving, it also carries significant risks and complications. Of these, ventilator-associated pneumonia (VAP) is one of the most severe, being associated with increased morbidity and duration of MV in the intensive care unit (ICU) [1,2]. Ventilator-associated tracheobronchitis (VAT) is believed to be an intermediate stage between colonization of the lower respiratory tract and VAP. However, more recent data suggests that VAT may be a separate entity that may

\footnotetext{
* Correspondence: drmartinloeches@gmail.com

${ }^{6}$ Critical Care Centre, Corporació Sanitària I Universitaria Parc Taulí, Hospital De Sabadell Institut Universitari UAB, Ciber Enfermedades Respiratorias, Parc Taulí, 108208 Sabadell, Barcelona, Spain

Full list of author information is available at the end of the article
}

contribute to increased length of ICU stay and longer duration of MV [3].

Both VAP and VAT are clinically characterized by presence of fever, mucopurulent bronchial secretions, and leukocytosis. In contrast to VAP, VAT does not involve the pulmonary parenchyma and, as a result, does not cause radiographic pulmonary infiltrates. Accurate diagnosis of VAT is challenging, as many conditions commonly encountered in critically ill patients (such purulent secretions, pulmonary edema or acute respiratory distress syndrome) can mimic its signs and symptoms. The current knowledge on VAT, in contrast to that on VAP, is recent and limited to a substantially lower number of large clinical studies. Our main objectives were to document reported practices of clinical and 
microbiological diagnosis of VAT and to evaluate perceptions of the impact of VAT on patient outcomes. This will serve as a first step of an international prospective study on VAT registered under number NCT01791530 (ClinicalTrials.gov).

\section{Materials and methods Study population}

Physicians with a major role in infection control practices and ICU clinical management were surveyed, and only one respondent per ICU was allowed. This study was approved by the ethics committee of Corporació Sanitaria Parc Taulí, Sabadell, Spain (reference number 2013515). Informed consent was not required as the survey consisted of a voluntary anonymous response to a web-based questionnaire, which did not include patient data. The web-based survey attempted to assess the responding physicians' individual perceptions of current clinical practices.

\section{Questionnaire}

We developed a web-based questionnaire with four parts (Additional file 1): (a) characteristics of the respondent and the ICU and hospital, (b) practices of clinical and microbiological diagnosis of VAT, (c) empirical antibiotic (ATB) therapy used after diagnosis, and (d) the perception of physicians regarding the clinical impact of VAT and the need for treatment. To evaluate diagnostic factors, we questioned investigations performed (for example, fiber-optic bronchoscopy versus less invasive techniques), culture (quantitative or semi-quantitative), and any complementary imaging studies. Regarding ATB use, we included questions on the nature of empirical therapy, combination use, timing of treatment commencement, and the use of inhaled ATB therapy for treatment of VAT. The questionnaire was concise and consisted strictly of multiple-choice questions in an attempt to improve the response rate. It was first developed in Spanish and then translated into English, French, and Portuguese by the Steering Committee members. We transferred the surveys to a web platform (ClinicalRec) - a fine-tuned, hosted web and data-mining platform designed specifically to perform and analyze clinical datato collect the data.

\section{Dissemination to target group}

The questionnaire was available online from 1 January to 31 March 2013. It was endorsed by SEMICYUC (Sociedad Española de Medicina Intensiva, Crítica y Unidades Coronaria), FEPIMCTI (Federación Panamericana e Ibérica de Sociedades de Medicina Crítica y Terapia Intensiva), and BRICNET (Brazilian Research in Intensive Care NETWORK). The members of the Steering Committee (local opinion leaders) were responsible for the distribution of the survey in their countries. The questionnaire was sent by e-mail to 1,036 physicians: $610(58.8 \%)$ in Spain $(\mathrm{n}=350)$, Portugal $(\mathrm{n}=50)$, and France $(\mathrm{n}=210)$, which formed the Spain, Portugal, and France (SPF) group, and 426 in the Latin American (LA) group. Table 1 shows the number of surveys sent by country. The survey was not distributed in the US, although one participant ICU which was part of a research network actively collaborating with different centers in Spain was included.

\section{Statistical analysis}

Descriptive statistics were used to characterize the study sample. We used chi-square and Mann-Whitney tests to compare survey characteristics of study participants and to make comparisons by country and region. Data were processed by using the Statistical Package of Social Sciences (SPSS) 13.0.1 standard version (IBM, Chicago, IL, USA). Response rates and sample characteristics were analyzed by using descriptive statistics. In descriptive data analysis, proportions (percentages) were reported. Statistical significance was defined as a $P$ value of less than 0.05 .

\section{Results}

A total of 288 ICUs from 16 different countries replied to the survey, representing a response rate of $27.8 \%$ $(288 / 1,036)$. Fifty-one percent $(n=147)$ were from the LA group, and 141 (49\%) from the SPF group (Figure 1). The number of individual responses per country is shown in Table 1. The main characteristics of the respondents and the ICUs were compared and are also presented in Table 2. In the SPF group as compared with

Table 1 Survey response rate

\begin{tabular}{lcc}
\hline Country & Total of sent surveys, $\mathbf{n}(\%)$ & Responses, $\mathbf{n}(\%)$ \\
\hline Spain & $350(33.8)$ & $92(26.3)$ \\
France & $210(20.3)$ & $32(15.2)$ \\
Portugal & $50(4.8)$ & $17(34.0)$ \\
Brazil & $182(17.6)$ & $61(33.5)$ \\
Colombia & $60(5.8)$ & $22(38.6)$ \\
Argentina & $50(4.8)$ & $17(34.0)$ \\
Chile & $30(2.9)$ & $12(40.0)$ \\
Ecuador & $20(1.9)$ & $12(60.0)$ \\
Peru & $20(1.9)$ & $7(35.0)$ \\
Mexico & $20(1.9)$ & $1(5.0)$ \\
Venezuela & $10(0.9)$ & $4(40.0)$ \\
Uruguay & $10(0.9)$ & $4(40.0)$ \\
Bolivia & $10(0.9)$ & $4(40.0)$ \\
Guatemala & $8(0.8)$ & $2(25.0)$ \\
Costa Rica & $5(0.5)$ & $1(20.0)$ \\
USA & $1(0.1)$ & $1(100)$ \\
\hline
\end{tabular}




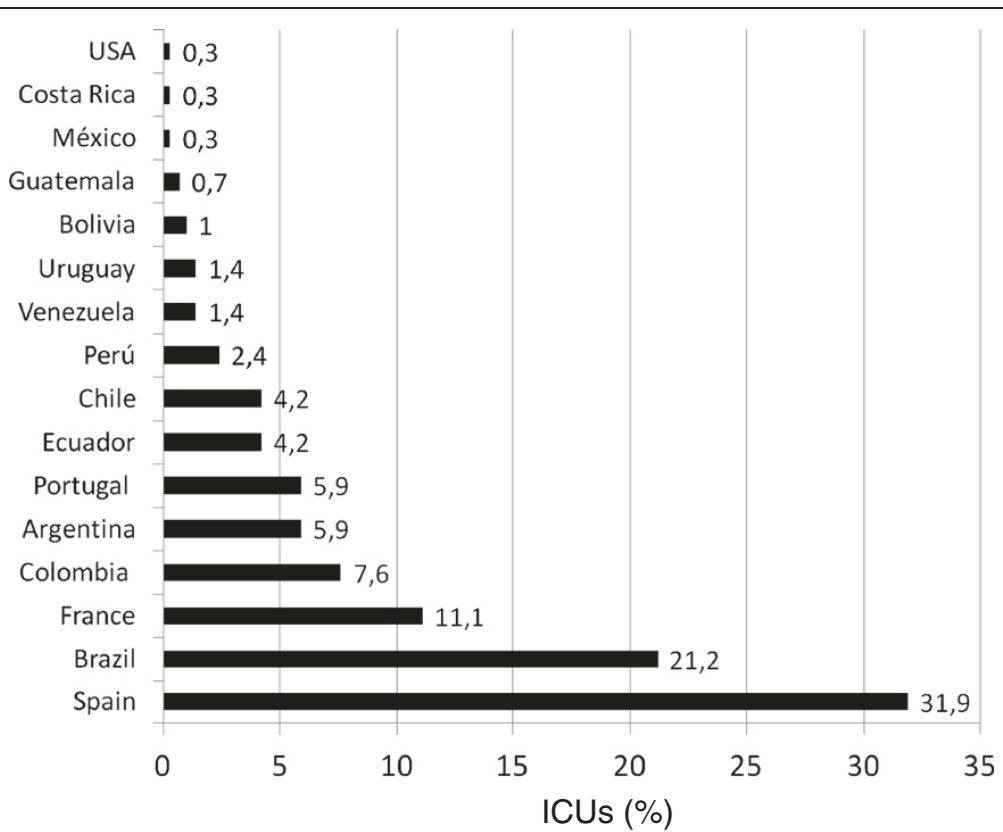

Figure 1 Percentage of intensive care units (ICUs) that responded to the survey out of a total of $\mathbf{2 8 8}$ responses. Data are presented according to the country of origin.

LA, more hospitals were in a public health system, had greater numbers of beds, and were more frequently university-associated. However, the only ICUs with more than 50 beds were reported in the LA group. There was no significant statistical difference when comparing the response of physicians according to the type of ICU (university versus non-university ICU), nor when comparing the number of ICU beds (less or more than 20).

\section{Diagnosis of ventilator-associated tracheobronchitis}

Almost all (99.7\%) of the respondents considered that ventilated patients are at risk of developing VAT. One hundred two respondents (35.5\%) considered that VAT is more frequent in all ICU ventilated patients irrespective of the type of admission diagnosis. Eighty-nine (30.9\%) respondents considered that patients admitted because of medical conditions are at higher risk of VAT, followed by neurological $(\mathrm{n}=53 ; 8.4 \%)$ and surgical $(n=20 ; 7.0 \%)$ patients.

The majority of respondents $(\mathrm{n}=228 ; 79.2 \%)$ make the diagnosis of VAT on the basis of both clinical and microbiological criteria. Forty (13.9\%) reported using clinical criteria alone, and 19 (6.6\%) consider it as a diagnosis of exclusion. Endotracheal aspirates were reported to be the most frequently used technique for the diagnosis of VAT (59.4\%), followed by bronchoalveolar lavage (BAL) (13.9\%) and multiple sampling techniques (12.2\%). BAL and mini-BAL techniques were more frequently employed by the LA group, whereas multiple sample techniques were more commonly used by the SPF group
(Table 3), and $47.6 \%(\mathrm{n}=137)$ used any bronchoscopic technique for diagnosis of VAT (Table 4). Whereas the use of bronchoscopic techniques is part of routine practice in only $3.1 \%$ of respondents, it is used in $35.8 \%$ when the chest $x$-ray (CXR) is not conclusive and in $8.7 \%$ when ATB treatment is started. Similarly, more than $50 \%$ of physicians requested a computed tomography $(\mathrm{CT})$ scan to confirm or exclude the diagnosis of VAT, $2.4 \%$ as routine practice, and $48.3 \%$ when CXR is inconclusive (Table 4).

Although the majority of respondents $(n=276 ; 95.8 \%)$ use microbiological findings to guide ATB treatment, more than half $(\mathrm{n}=170 ; 59.0 \%)$ do not perform a Gram stain on the respiratory sample. Sixty-six (22.9\%) reported that they do not request quantitative cultures of respiratory secretions as routine practice, and this occurred more frequently in the SPF group (Table 4).

\section{Treatment of ventilator-associated tracheobronchitis}

Approximately half (50.3\%) of the respondents agreed that patients diagnosed with VAT should receive ATBs. Only $24.3 \%(n=70)$ routinely prescribed ATBs, whereas $42.0 \%(\mathrm{n}=121)$ only prescribed ATBs in the presence of hemodynamic instability. Conversely, 26\% $(n=75)$ of physicians considered that VAT should not be treated with ATB, and $7.6 \%(n=22)$ answered that they do not have a clear opinion on the most appropriate treatment. A total of $90.3 \%(n=260)$ of the responders indicated that the duration of MV helped in the decision of ATB treatment; however, only $50 \%$ of them indicated this 
Table 2 Characteristics of the respondents and intensive care unit setting

\begin{tabular}{ccccc}
\hline Characteristics & Global & $\begin{array}{c}\text { SPF } \\
\text { group }\end{array}$ & $\begin{array}{c}\text { Latin American } \\
\text { group }\end{array}$ & $P$ value $^{\mathrm{a}}$ \\
& $\mathrm{n}=288$ & $\mathrm{n}=141$ & $\mathrm{n}=147$ \\
& $\mathrm{n}(\%)$ & $\mathrm{n}(\%)$ & $\mathrm{n}(\%)$
\end{tabular}

Number of beds
in ICU

\begin{tabular}{|c|c|c|c|c|}
\hline$>50$ beds & $11(3.8)$ & - & $11(7.5)$ & 0.003 \\
\hline $21-50$ beds & $79(27.4)$ & $40(28.4)$ & $39(26.5)$ & 0.82 \\
\hline $10-20$ beds & $140(48.6)$ & $80(56.7)$ & $60(40.8)$ & 0.01 \\
\hline$<10$ beds & $58(20.1)$ & $21(14.9)$ & $37(25.2)$ & 0.04 \\
\hline \multicolumn{5}{|l|}{ ICU type } \\
\hline General & $278(96.5)$ & 137 (97.2) & $141(95.9)$ & 0.79 \\
\hline Cardiac surgery & $3(1.0)$ & - & $3(2.0)$ & 0.26 \\
\hline Neurotrauma & $2(0.7)$ & - & $2(1.4)$ & 0.49 \\
\hline Surgical & $2(0.7)$ & $2(1.4)$ & - & 0.46 \\
\hline Respiratory & $2(0.7)$ & $1(0.7)$ & $1(0.7)$ & 1.00 \\
\hline Trauma & $1(0.3)$ & $1(0.7)$ & - & 0.98 \\
\hline \multicolumn{5}{|l|}{$\begin{array}{l}\text { Number of beds } \\
\text { in hospital }\end{array}$} \\
\hline$>500$ beds & $103(35.8)$ & $79(56.0)$ & $24(16.3)$ & $<0.001$ \\
\hline $201-500$ beds & $107(37.2)$ & 55 (39.0) & $52(35.4)$ & 0.60 \\
\hline $100-200$ beds & $50(17.4)$ & $7(5.0)$ & $43(29.3)$ & $<0.001$ \\
\hline$<100$ beds & $28(9.7)$ & - & $28(19.0)$ & $<0.001$ \\
\hline \multicolumn{5}{|l|}{ Hospital type } \\
\hline Public & $188(65.3)$ & $133(94.3)$ & $55(37.4)$ & $<0.001$ \\
\hline Private & $78(27.1)$ & $5(3.5)$ & $73(49.7)$ & $<0.001$ \\
\hline Mixed & $22(7.6)$ & $3(2.1)$ & 19 (12.9) & 0.002 \\
\hline
\end{tabular}

Academic degree

$\begin{array}{lllll}\text { University } & 190(66.0) & 104(73.8) & 86(58.5) & 0.009\end{array}$

$\begin{array}{lllll}\text { No university } & 98(34.0) & 37(26.2) & 61(41.5) & 0.009\end{array}$

${ }^{a}$ All comparisons were made between Spain, Portugal, and France (SPF) and Latin American groups. ICU, intensive care unit. option in the survey in regard to the best treatment option for VAT (Table 5).

Intravenous (IV) monotherapy (62.5\%) is the first choice of ATB treatment for VAT and was more frequently supported by the SPF group, followed by IV ATB combination (20.8\%) and then IV and nebulized ATB. The use of nebulized ATB is more frequently reported by the LA group compared with the SPF group (Table 5).

The majority of respondents (73.3\%) started ATB treatment within 12 hours of VAT diagnosis. Initiation of treatment after 24 hours of VAT diagnosis was more commonly reported by the SPF group $(12.1 \%)$ as compared with the LA group (4.8\%). More than half (66.7) indicated they favored ATB treatment with a duration of between 7 and 10 days. Half of the respondents preferred to de-escalate therapy when the results of microbiology tests are available. Surprisingly, only $24 \%$ indicated a preference for a short course of ATB treatment $(<7$ days). The empiric antimicrobial regimens for early- and late-onset VAT are shown in Figures 2 and 3 , respectively.

\section{Impact of ventilator-associated tracheobronchitis}

Finally, 94.1\% $(n=274)$ of respondents believe that the development of VAT is associated with longer duration of MV. Two hundred sixty-nine (93.4\%) assume that a VAT episode is associated with increased ICU length of stay, and this perception is greater in the LA group (97.3\%) as compared with the SPF group $(89.4 \%, P<0.05)$. Half of the physicians considered that VAT increases the risk of mortality, and this perception is again greater in the LA group as compared with the SPF group (58.5\% versus $41.1 \%, P<0.05)$.

\section{Discussion}

This is the first international survey that has aimed to evaluate perceptions of impact and self-reported practices in the diagnosis and treatment of VAT. We consider that the present survey is relevant to increase the current knowledge of VAT. There are several conflicting

Table 3 Techniques used for the diagnosis of ventilator-associated tracheobronchitis

\begin{tabular}{|c|c|c|c|c|c|}
\hline Technique & $\begin{array}{c}\text { Global } \\
n=288 \\
n(\%)\end{array}$ & $\begin{array}{l}\text { SPF group } \\
n=141 \\
n(\%)\end{array}$ & $\begin{array}{l}\text { Latin American group } \\
\qquad \begin{array}{c}n=147 \\
n(\%)\end{array}\end{array}$ & $\begin{array}{c}P \\
\text { value }^{a}\end{array}$ & OR $(95 \% \mathrm{Cl})^{\mathrm{a}}$ \\
\hline Endotracheal aspirate (ETA) & $171(59.4)$ & $87(61.7)$ & $84(57.1)$ & 0.50 & ND \\
\hline Bronchoalveolar lavage (BAL) & $40(13.9)$ & $12(8.5)$ & $28(19.0)^{a}$ & 0.01 & $0.4(0.2-0.8)$ \\
\hline ETA plus other techniques & $35(12.2)$ & $27(19.1)$ & $8(5.4)^{a}$ & 0.001 & $4.1(1.7-10.3)$ \\
\hline Mini-BAL & $21(7.3)$ & $4(2.8)^{a}$ & $17(11.6)^{a}$ & 0.009 & $0.2(0.07-0.08)$ \\
\hline Protected specimen brush & $4(1.4)$ & $3(2.1)$ & $1(0.7)$ & 0.58 & ND \\
\hline No response & $17(5.9)$ & $8(5.7)$ & $9(6.1)$ & 1.00 & ND \\
\hline
\end{tabular}

${ }^{a}$ All comparisons were made between Spain, Portugal, and France (SPF) and Latin American groups. Cl, confidence interval; ND, not determined; OR, odds ratio. 
Table 4 Microbiological techniques and complementary studies used to the diagnosis of ventilator-associated tracheobronchitis

\begin{tabular}{|c|c|c|c|c|c|}
\hline Questions & $\begin{array}{c}\text { Global } \\
n=288 \\
n(\%)\end{array}$ & $\begin{array}{l}\text { SPF group } \\
\begin{array}{c}n=141 \\
n(\%)\end{array}\end{array}$ & $\begin{array}{l}\text { Latin American group } \\
\qquad \begin{array}{c}n=147 \\
n(\%)\end{array}\end{array}$ & $\begin{array}{c}P \\
\text { value }\end{array}$ & OR $(95 \% \mathrm{Cl})$ \\
\hline \multicolumn{6}{|l|}{ Quantitative cultures } \\
\hline Yes & $217(75.3)$ & $97(68.8)^{\mathrm{a}}$ & $120(81.6)$ & 0.01 & $0.5(0.3-0.9)$ \\
\hline No & $66(22.9)$ & $42(29.8)^{\mathrm{a}}$ & $24(16.4)$ & 0.01 & $2.2(1.9-3.9)$ \\
\hline NR & $5(1.7)$ & $2(1.4)$ & $3(2.0)$ & 1.00 & ND \\
\hline \multicolumn{6}{|l|}{ Gram stain technique } \\
\hline Yes & $116(40.3)$ & $62(44.0)$ & $54(36.7)$ & 0.25 & ND \\
\hline No & $170(59.0)$ & $78(55.3)$ & $92(62.6)$ & 0.25 & ND \\
\hline NR & $2(0.7)$ & $1(0.7)$ & $1(0.7)$ & 1.00 & ND \\
\hline \multicolumn{6}{|l|}{ Bronchoscopy for the diagnosis of VAT } \\
\hline Never & $151(52.4)$ & $73(51.8)$ & $78(53.1)$ & 0.92 & ND \\
\hline Only when the chest $x$-ray is not conclusive & $103(35.8)$ & $50(35.5)$ & $53(36.1)$ & 1.00 & ND \\
\hline Only if I decide to start ATBs & $25(8.7)$ & $13(9.2)$ & $12(8.2)$ & 0.91 & ND \\
\hline Always & $9(3.1)$ & $5(3.5)$ & $4(2.7)$ & 0.95 & ND \\
\hline \multicolumn{6}{|l|}{ CT scan for the diagnosis of VAT } \\
\hline Never & $142(49.2)$ & $82(58.2)^{\mathrm{a}}$ & $60(40.8)$ & 0.005 & $2.0(1.2-3.3)$ \\
\hline Only when the chest $x$-ray is not conclusive & $139(48.3)$ & $58(41.1)^{\mathrm{a}}$ & $81(55.1)$ & 0.02 & $0.5(0.3-0.9)$ \\
\hline Always & $7(2.4)$ & $1(0.7)$ & $6(4.1)$ & 0.14 & ND \\
\hline
\end{tabular}

${ }^{a}$ All comparisons were made between Spain, Portugal, and France (SPF) and Latin American groups. ATB, antibiotic; Cl, confidence interval; CT, computed tomography; ND, not determined; NR, no response; OR, odds ratio; VAT, ventilator-associated tracheobronchitis.

results regarding the clinical implications of VAT, and the present survey provides a path toward meaningful research questions for future clinical studies. The main conclusions of the present study are that VAT is perceived as a common complication of MV in ICU patients and is a diagnosis based not only on clinical criteria but also on non-invasive techniques and microbiological confirmation and that half of physicians surveyed use systemic ATBs to treat VAT as they believe that VAT is associated with a longer duration of MV and longer ICU length of stay.

The true incidence of VAT is not currently known. VAT is recognized by the Centers of Disease Control and Prevention (CDC)/National Healthcare Safety Network [4] as an individual clinical entity. As the clinical relevance of VAT seems to be increasing, it is necessary to further delineate its incidence in a study that applies a widely accepted definition. A large multicenter international study is planned in order to answer some of the questions presented in this survey. The goal of the present survey was to determine the importance of VAT and physicians attitudes based on the answers taken from 288 ICUs in Europe and Latin America.

The majority of respondents $(>90 \%)$ to the present survey agreed that patients under MV have a significant risk of developing VAT, and they perceived that this risk was even higher in medical patients. This finding is in opposition to that of the study by Malacarne and colleagues [5], who in a prospective epidemiological study conducted in 71 Italian ICUs with 9,493 consecutive patients found that surgical patients were more likely to develop VAT than medical patients (odds ratio (OR) of 1.64). According to the current definition, as recently published by the CDC, a diagnosis of VAT is made if there is absence of pneumonia in the $\mathrm{x}$-ray and at least two of the following findings: (1) fever $\left(>38^{\circ} \mathrm{C}\right)$, (2) cough, (3) new or increased production of sputum, (4) rhonchi, and (5) wheezing, and at least one of the following: (a) positive culture obtained by deep tracheal aspirate or bronchoscopy and (b) positive laboratory test on respiratory secretions [4].

Similarly, the European Respiratory Society, European Society of Clinical Microbiology and Infectious Diseases, and European Society of Intensive Care Medicine taskforce requires a positive culture of respiratory secretions as a mandatory item in the diagnosis of VAT [6]. In the present survey, almost $80 \%$ of physicians routinely diagnosed VAT with the assistance of microbiological studies, and a minority (13.9\%) relied solely on clinical assessment. As expected, non-invasive techniques were more frequently preferred to obtain samples and achieve microbiological confirmation. Although the use of quantitative 
Table 5 Antibiotic treatment of ventilator-associated tracheobronchitis

\begin{tabular}{|c|c|c|c|c|c|}
\hline Questions & $\begin{array}{c}\text { Global } \\
n=288 \\
n(\%)\end{array}$ & $\begin{array}{c}\text { SPF group } \\
n=141 \\
n(\%)\end{array}$ & $\begin{array}{l}\text { Latin American group } \\
\qquad \begin{array}{c}n=147 \\
n(\%)\end{array}\end{array}$ & $\begin{array}{c}P \\
\text { value }^{a}\end{array}$ & OR $(95 \% \mathrm{Cl})^{2}$ \\
\hline \multicolumn{6}{|l|}{ All VAT patients should receive ATB treatment? } \\
\hline Yes & $121(42.0)$ & $59(41.8)$ & $62(42.2)$ & 1.00 & ND \\
\hline No & $75(26.0)$ & $31(22.0)$ & $44(29.9)$ & 0.16 & ND \\
\hline Only in patients with cardiovascular failure & $70(24.3)$ & $41(29.1)$ & $29(19.7)$ & 0.08 & $1.6(0.9-2.9)$ \\
\hline Unknown & $22(7.6)$ & $10(7.1)$ & $12(8.2)$ & 0.90 & \\
\hline \multicolumn{6}{|c|}{ Which is the most appropriate treatment for VAT? } \\
\hline Broad-spectrum IV ATBs & $84(29.2)$ & $37(26.2)$ & $47(32.0)$ & 0.34 & ND \\
\hline Narrow-spectrum IV ATBs & $20(6.9)$ & $15(10.6)$ & $5(3.4)$ & 0.002 & $3.3(1.1-10.9)$ \\
\hline Select ATBs according to MV days & $145(50.3)$ & $74(52.5)$ & $71(48.3)$ & 0.55 & ND \\
\hline Nebulized ATBs & $6(2.1)$ & $2(1.4)$ & $4(2.7)$ & 0.71 & ND \\
\hline Broad-spectrum IV ATBs + nebulized ATBs & $7(2.4)$ & $1(0.7)$ & $6(4.1)$ & 0.14 & ND \\
\hline Never & $26(9.0)$ & $12(8.5)$ & $14(9.5)$ & 0.92 & ND \\
\hline \multicolumn{6}{|c|}{ Which is the most appropriate option for treatment of VAT? } \\
\hline IV ATBs in monotherapy & $180(62.5)$ & $99(70.2)$ & $81(55.1)$ & 0.01 & $1.9(1.1-3.2)$ \\
\hline IV ATBs in combination & $60(20.8)$ & $20(20.6)$ & $31(21.1)$ & 0.16 & ND \\
\hline IV ATBs + nebulized ATBs in monotherapy & $27(9.4)$ & $7(5.0)$ & $20(13.6)$ & 0.02 & $0.3(0.1-0.8)$ \\
\hline IV ATBs + nebulized ATBs in combination & $16(5.6)$ & $2(1.4)$ & $14(9.5)$ & 0.006 & $0.1(0.02-0.6)$ \\
\hline No replyTiming to start ATB treatment? & $5(1.7)$ & $4(2.8)$ & $1(0.7)$ & 0.34 & ND \\
\hline$<12$ hours & $211(73.3)$ & $96(68.1)$ & $115(78.2)$ & 0.07 & $0.5(0.3-1.0)$ \\
\hline 13-24 hours & $44(15.3)$ & $23(16.3)$ & $21(14.3)$ & 0.75 & ND \\
\hline$>24$ hours & $24(8.3)$ & $17(12.1)$ & $7(4.8)$ & 0.04 & $2.7(1.01-7.5)$ \\
\hline Never ATB treatment & $9(3.1)$ & $5(3.5)$ & $4(2.7)$ & 0.95 & ND \\
\hline \multicolumn{6}{|l|}{ ATB duration } \\
\hline 7-10 days & $25(8.7)$ & $7(5.0)$ & $18(12.2)$ & 0.04 & $0.3(0.1-0.9)$ \\
\hline 7-10 day but de-escalation & $167(58.0)$ & $84(59.0)$ & $83(56.5)$ & 0.67 & ND \\
\hline 14 days & $1(0.3)$ & 0 & $1(0.7)$ & 1.00 & ND \\
\hline Until clinical resolution & $22(7.6)$ & $13(9.2)$ & $9(6.1)$ & 0.44 & ND \\
\hline$<7$ days & $71(24.7)$ & $35(24.8)$ & $36(24.5)$ & 1.00 & ND \\
\hline No reply & $2(0.7)$ & $2(1.4)$ & 0 & 0.90 & ND \\
\hline
\end{tabular}

${ }^{a}$ All comparisons were made between Spain, Portugal, and France (SPF) and Latin American groups. ATB, antibiotic; Cl, confidence interval; IV, intravenous; MV, mechanical ventilation; ND, not determined; NR, no response; OR, odds ratio; VAT, ventilator-associated tracheobronchitis.

cultures of respiratory secretions could be helpful to differentiate VAT from colonization, invasive techniques are not mandatory for VAT diagnosis. It was therefore surprising that invasive techniques are used by almost half of respondents. This finding is more frequent in the LA group than the SPF group.

The subjectivity and variability inherent in interpretation of CXRs in mechanically ventilated patients make chest imaging ill suited for inclusion in a definition algorithm to be used for the potential purposes of public reporting, inter-facility comparisons, and pay-for-reporting and payfor-performance programs. Several authors $[7,8]$ have proposed the use of CT lung scans and this recommendation is followed by half of the respondents to the survey. Nevertheless, it is important to consider whether a CT scan for this purpose is cost-effective and safe for critically ill patients. Ventilated patients are at high risk for complications en route, and in addition transport outside the ICU has been reported to be an independent risk factor for VAP (OR 2.9, 95\% confidence interval 1.4 to 5.7 ) $[8,9]$. A recent observational cross-sectional study of adult patients in the emergency department found that CXRs demonstrated poor sensitivity and positive predictive value for detecting pulmonary opacities when compared with chest $\mathrm{CT}$ for routine clinical care $[10,11]$. It remains unclear whether the use of chest 


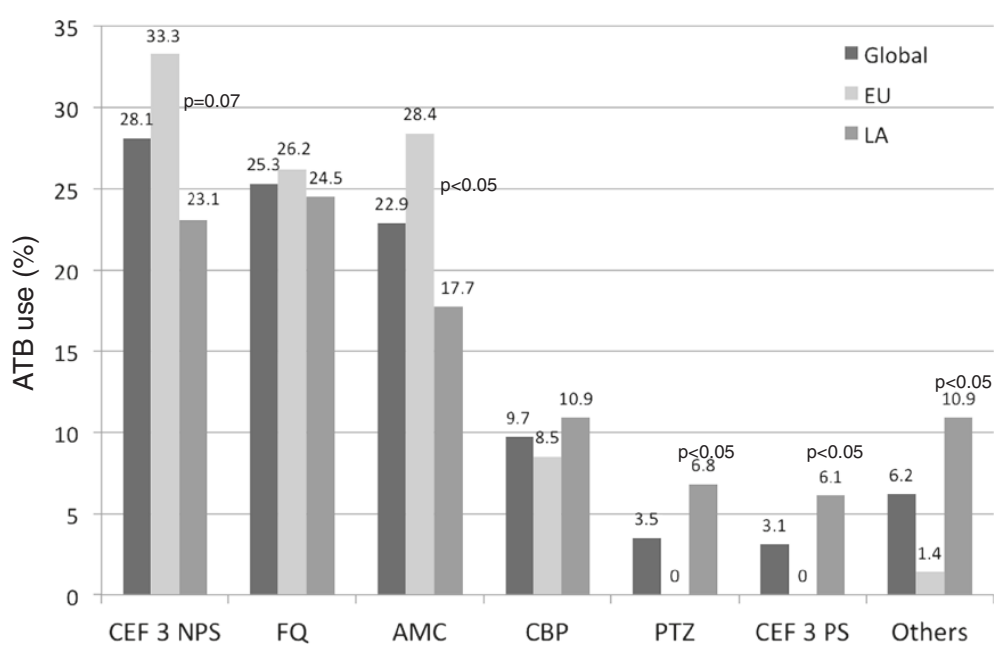

Figure 2 Empiric antibiotic therapy for early ventilator-associated tracheobronchitis. AMC, amoxicillin/clavulanate; AMK, Amikacin; CBP, carbapenem; CEF3 NPS, third-generation non-Pseudomonal cephalosporins; CEF3 PS, third-generation Pseudomonal cephalosporins; EU, European Union group; FQ, fluoroquinolones; LA, Latin American group; PTZ, Piperacillin/Tazobactam; Vanco: vancomycin.

CT is cost-effective or even necessary for the management of suspected VAT.

The ATB treatment of VAT remains controversial [12]. In the survey, half of the respondents reported that the duration of MV is an important factor to consider when deciding on administration of ATBs to patients with VAT. The use of ATBs in VAT has been evaluated in two recent randomized controlled trials. Palmer and colleagues [13] found faster weaning and less use of systemic ATB when nebulized ATBs were administered. Nseir and colleagues [14] found a lower mortality rate and more MV-free days. Although the administration of aerosolized ATB in patients with uncomplicated VAT is an attractive approach, it is reported by only the minority

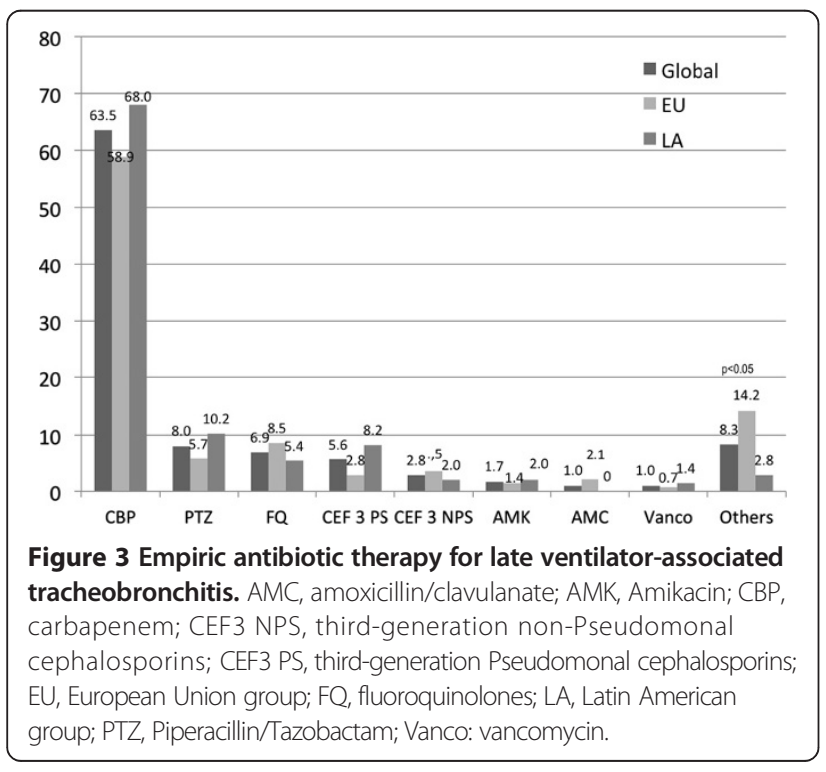

of the respondents. In our survey, this practice is more frequent in LA. Well-designed prospective studies are needed in order to further delineate the best therapeutic approach for suspected VAT.

We acknowledge limitations to the present survey. First, the present study may have a bias selection as VAT may represent an important clinical entity for respondents. Second, although we sought to survey the ICU physician most involved in the decision-making process related to ICU infections, it may represent the personal opinion of the respondents and may not reflect hospital or country-wide policies. Third, we could not be completely sure that respondents were not using VAT and VAP answers in an interchangeable fashion. However, questions about VAT were formulated with closed answers, and questions related to VAP were made in order to avoid confusion and misinterpretation between these two entities. Fourth, we recognize that self-reported practices in a survey may not reflect actual practice of the respondents, a limitation inherent in the nature of all surveys. Finally, this survey comes from only three European and 13 LA countries and thus cannot represent the opinions of these entire communities.

\section{Conclusions}

VAT is recognized as a frequent complication of MV. However, subjective components within VAT definition and diagnosis may impact the reliability and accuracy of case identification. VAT represents a clinical entity that is closer to the clinical reality than more strict criteria usually considered in most clinical published studies. Given the perceived increasing incidence of VAT and its importance as a possible risk factor for VAP and other adverse outcomes, a large multicenter international 
prospective study, with standardized clinical and microbiologic criteria for VAT diagnosis, needs to be performed. This should aim to validate an accepted definition of VAT, determine its incidence, and further delineate its impact on clinically relevant outcomes.

\section{Key messages}

- Ventilator-associated tracheobronchitis is perceived as a frequent complication of mechanical ventilation.

- The diagnosis of ventilator-associated tracheobronchitis is usually based on a combination of clinical and microbiological criteria.

- More than half of respondents did not perform a Gram stain on the respiratory sample and one out of four did not request a sample for quantitative culture in the diagnosis of ventilator-associated tracheobronchitis.

- Half of physicians reported prescribing broad-spectrum systemic antibiotics for the treatment of ventilator-associated tracheobronchitis.

- The majority of physicians believed that ventilator-associated tracheobronchitis is associated with a longer duration of mechanical ventilation and longer intensive care unit length of stay.

\section{Additional file}

Additional file 1: Survey submitted for the TAVeM group. Web-based questionnaire for the ventilator-associated tracheobronchitis (VAT) in the Intensive Care Unit International Online Survey.

\section{Abbreviations}

ATB: antibiotic; BAL: bronchoalveolar lavage; CDC: Centers of Disease Control and Prevention; CT: computed tomography; CXR: chest x-ray; ICU: intensive care unit; IV: intravenous; LA: Latin American; MV: mechanical ventilation; OR: odds ratio; SPF: Spain, Portugal, and France; VAP: ventilator-associated pneumonia; VAT: ventilator-associated tracheobronchitis.

\section{Competing interests}

The authors declare that they have no competing interests. The study was endorsed by SEMICYUC (Sociedad Española de Medicina Intensiva, Crítica y Unidades Coronaria) and FEPIMCTI (Federación Panamericana e Ibérica de Sociedades de Medicina Crítica y Terapia Intensiva). The endorsing societies had no role in study design; collection, analysis, or interpretation of data; writing of the manuscript; or the decision to submit the manuscript for publication. The content is solely the responsibility of the authors and does not necessarily represent the official views of the societies.

\section{Authors' contributions}

IM-L assisted in the design of the study, coordinated patient recruitment, analyzed and interpreted the data, and helped to make substantial contributions to the concept, design, analysis, and interpretation of data. He assisted in writing the manuscript, was involved in revising it critically for important intellectual content, revised the final version, and acted as guarantor of/person responsible for the entire manuscript. The TAVeM group made important contributions to the acquisition and analysis of data. AR assisted in the design of the study, coordinated patient recruitment, analyzed and interpreted the data, and helped to make substantial contributions to the concept, design, analysis, and interpretation of data. He assisted in writing the manuscript and revised the final version. PP, JS, SN, and DC assisted in the design of the study, coordinated patient recruitment, analyzed and interpreted the data, and assisted in writing the manuscript and were involved in revising it critically for important intellectual content. All authors read and approved the final manuscript.

\section{Acknowledgments}

We thank Alexis Tcach (ClinicalRec, Buenos Aires, Argentina) for the informatics support to carry out the survey, Luciano Rodriguez for assistance in data entry, and Craig Dunlop for English editing. This study is a collaboration of Sociedad Española de Medicina Intensiva, Critica y Unidades Coronarias (SEMICYUC) and Federación Panamericana e Ibérica de Sociedades de Medicina Crítica y Terapia Intensiva (FEPIMCTI). The writing committee of the study takes responsibility for the content and integrity of this article. Writing Committee: Alejandro Rodríguez (Hospital Joan XXIII Critical Care Department/IISPV/URV/CIBERES, Tarragona, Spain); Ignacio Martín-Loeches (Critical Care Centre Corporació Sanitària I Universitaria Parc Taulí/UAB/CIBERES, Sabadell, Spain); Pedro Póvoa (Polyvalent Intensive Care Unit, São Francisco Xavier Hospital, Lisboa, Portugal); Saad Nseir (Pôle de Réanimation, CHU de Lille, France); Jorge Salluh (associate researcher - D'OR Institute for Research and Education Postgraduate Program - Instituto Nacional de Câncer Rio de Janeiro, Brazil); and Daniel Curcio (Hospital de Chivilcoy, Buenos Aires, Argentina).

\section{TAVeM group}

Study Coordinators: Ignacio Martín-Loeches (Corporació Sanitaria Parc Taulí Sabadell, Spain) and Alejandro Rodriguez (Hospital Universitario Joan XXIII - URV IISPV, Tarragona, Spain); Steering Committee: José Cuñat (Hospital Universitario La Fe - Valencia, Spain - SEMICYUC); F. Álvarez-Lerma (Hospital del Mar- Barcelona, Spain - SEMICYUC) Sebastián Ugarte (Chile - FEPIMCTI); Carmelo Dueñas (ColombiaFEPIMCTI); Jorge Sinclair (Panamá - FEPIMCTI); Daniel Curcio (Hospital Municipal Chivilcoy - Buenos Aires, Argentina); Pedro Povoa (Polyvalent Intensive Care Unit, São Francisco Xavier Hospital, Lisboa, Portugal); Saad Nseir (Pôle de Réanimation, CHU de Lille, France); Jorge Salluh (Associate reseacher - D'OR Institute for Research and Education Postgraduate Program - Instituto Nacional de Câncer Rio de Janeiro, Brazil). Andorra: Antonio Margarit Ribas (Hospital Nostra Senyora de Meritxell Escaldes-Engordany); Argentina: Daniel Curcio, Fernando San Rome, Alexis Tcach (Hospital Municipal Chivilcoy - Chivilcoy), Christian Dellera, Darío Barrios, Ernesto Illiovich (Hospital Dr. Julio C. Perrando - Resistencia); María Gabriela Rodríguez Álvarez, Alex Tamayo, Marcos Wilches, Lorena Molocznik (Hospital Municipal Eva Perón - Merlo), Rubén O. Fernández, Mónica Grilli, Natalia Moyano (Hospital Español - Mendoza); Graciela Zakalik, Angela M. Sánchez, Adrian A. Marín (Hospital Luis Lagomaggiore - Mendoza), Roberto Santa Cruz, Mario Araujo; Hugo Culaccioni (Hospital Regional Rio Gallegos - Río Gallegos), Jorge Arroyo, Fernando Fernández, Guillermo Soria (Hospital Central Mendoza); Daniel Duarte, Héctor Herrera, Romina Nicastro (CEMEP - Rio Grande); Fernando Lipovestky, Diego Pereyra, Sandra Arcieri (Hospital Universitario UAI - Buenos Aires); Marcelino Javier Díaz, Luís JJ Ranieri, Roberto Giménez (Sanatorio Santa Fe - Santa Fe); Fabian M Galeano (Hospital Saturnino Unzue - 25 de Mayo); Alex Tamayo Reyes, Luís González, Julia Sakugawa (Hospital Provincial de Moreno - Moreno); Cesar J Pucci, Sonia Farías, Diego Pereyra (SOIF SRL - Villa Mercedes); Christian Dellera, Darío Barrios (Hospital Dr. Julio C Perrando - Resistencia); Abel Cahuana, Ivan Vite Acosta (Sanatorio San José - Buenos Aires); Daniel U Castro, Luis A Bustamante, Marcia C Nonino (Hospital Delicia Concepción Masvernat Concordia); Bolivia: Gustavo La Fuente Zerain, Sergio Peca Charocsi, Rubén Casanova (Hospital Universitario Japonés - Santa Cruz de la Sierra); Carlos Ibáñez Guzmán (Hospital Obrero No 1 - La Paz); Brazil: Péricles Almeida Delfino Duarte ( Hospital U. do Oeste do Paraná / Hospital do Câncer /UOPECCAN/ Hospital São Lucas-FAG - Cascavel); Ricardo Goulart (Hospital Vitoria - Sao Paulo); Carlos Nassif (Hospital Nove de Julho - Sao Paulo); Céu Cordeiro Gonçalves Moura (Hospital Alvorada Moema - UTI 1 São Paulo), Sylas Bezerra Cappi (Hospital Alvorada Moema - UTI 2 - Sao Paulo); Thiago Lisboa (Hospital de Clinicas / Hospital Santa Rita -Complexo Hospitalar Santa Casa - Porto Alegre); Joa Geraldo Simoes Houly (Hospital Santa Paula - Sao Paulo); Isabela Miranda Lopes (Hospital de Clinicas Caieiras - Sao Paulo); Luciane Marques Bertoldo Viñas (Hospital ABC - Sao Bernardo do Campo); Thiago Domingos Correa, Eliezer Silva (Hospital Israelita Albert Einstein); Pedro Azambuja, Marcos Freitas Knibel (Hospial Sao Lucas - Rio de Janeiro); Alessandro Nascimento Araújo Souza (Hospital Portuges - Salvador); Bruno Toldo, Octavio Ranzani (Hospital da Luz Santo Amaro); Cauê Matte (Hospital Santa Izabel - Salvador); Israel Pinheiro 
Campos (Hospital Paulistano - Sao Paulo); Felipe Dal Pizzol (Hospital São José Criciúma); Laura Darriba W.Camargo, Eduardo de Souza Pacheco (Hospital da Luz - Sao Paulo); Antonio Paulo Nassar Junior (Hospital São Camilo - Santana); Sandro Oliveira (Hospital Bangu - Rio de Janeiro); Elmo Pereira Jr. (Hospital Norte Dor - Rio de Janeiro); Jair Biatto (Hospital Santa Rita - Maringá); Marcellus Gazola Grillo (Hospital Evangelico - Cachoeiro de Itapemirim); Ricardo Lima, Daniel Cutrim (Hospital Samaritano - Rio de Janeiro); Ludhmila Hajjar (Instituto do Cancer / InCor - Sao Paulo); Vicente Cés de Souza Dantas (Hospital Pasteur - Rio de Janeiro); Cesar Biselli Ferreira, Luiz Marcelo Sá (HCFMUSP - UTI Emergencias Cirúrgicas e Trauma - Sao Paulo); Antonio Carlos Babo Rodrigues (Hospital Estadual Getulio Vargas - Rio de Janeiro); Edison Moraes Rodrigues Filho (Hospital Nossa Senhora da Conceição - Porto Alegre); Jose Roberto Aldrighi (Hospital São Cristovão - Sao Paulo); Suzana Lobo (Hospital de Base - São José do Rio Preto); Lígia Rabello, Rodrigo Serafim (Hospital Copa Dor - Rio de Janeiro); Amadeu Martinez (Hospital Espanhol - Salvador); Jose Jorge Soares Netto (Instituto Nacional de Câncer II - Rio de Janeiro); Fernando Colombari (Hospital Alemão Oswaldo Cruz- Sao Paulo); Marcio Andrade Martins (Hospital do Coração - Camboriú); Rodrigo Hatum (Hospital Total Cor - Rio de Janeiro); Mirna Matsui (Hospital UFGD - Dourados); Leandro Utino Taniguchi (HC-FMUSP - UTI Pronto-Socorro da Clínica Médica - Sao Paulo); Luciano Azevedo (Hospital Sirio-Libanes - Sao Paulo); Otavio Ranzani (HCFMUSP - UTI Respiratoria/Pneumologia) Sergio Kiffer Macedo (Hospital São José da Avaí - Itaperuna); Marcio Osório Guerreiro (Hospital Universitario São Francisco de Paula - Pelotas); Jorge Luis dos Santos Valiatti (Hospital Padre Albino - Catanduva); Ludhmila Hajjar (InCor), Dyanne Moyses Dalcomune (Hospital Meridional - Cariacica); Ulysses Vasconcellos de Andrade e Silva (Hospital Fundação Pio XII/Hospital de Câncer - Barretos); Eraldo de Azevedo Lucio (Hospital São Francisco/Santa Casa de Porto Alegre - Porto Alegre); Celina Acra (Casa de Saúde Santa Lúcia - Rio de Janeiro); Felipe Hernriques Alves da Silva (Instituto Nacional de Câncer I - Rio de Janeiro); André M Japiassu (IPEC/FioCruz - Rio de Janeiro); Fabio Ferreira Amorim (Hospital Regional de Samambaia - Brasília); Rubens Costa Filho, Dominique Thielmann (Hospital Procardíaco - Rio de Janeiro); Danielle (Hospital Municipal São José - Joinville); Marcelo de Oliveira Maia (Hospital Santa Luzia Brasília); Jorge Hoher (Santa Casa Porto Alegre - Porto Alegre); Marcelo Park (Hospital das Clinicas - Sao Paulo); Walter Homena (Hospital Barra Dor - UTI Pós-operatória - Rio de Janeiro); Chile: Ronald Pairumani Medrano, Jorge Silva Sepulveda, Ruth Rosales Chacón (Hospital Barros Luco Trudeau Santiago); Eduardo Tobar, Ricardo Gálvez, Cecilia Luengo, Nivia Estuardo (Hospital Clínico Universidad de Chile - Santiago); Eduardo Labarca, Ana M Donoso, Elizabeth Barthel (Hospital Naval Almirante Nef - Viña del Mar); Alejandro Bruhn (Hospital Clínico Pontificia Universidad Católica de Chile Santiago); Juan E Sánchez Valenzuela, José M Arancibia Henriquez, David Gallardo Pérez (Hospital San Juan de Dios - Santiago); Hernán Figueroa Riquelme, Jorge Becerra, José Pinto (Hospital Juan Noe - Arica); Ricardo Morales Inzunza, Vinko Tomicic Flores (Clínica Las Lilas - Santiago); Francisco Arancibia, María Paz Saavedra (Instituto Nacional del Tórax - Santiago); Colombia: Carmelo Dueñas (Gestión Salud - Cartagena); Juan C Fernández Mercado, Orlando Girón Florez, Mauricio Castro Vivero (Clínica CRECER Cartagena); David Yepes, Jorge Bejarano, Juan Carlos Arango (Clínica CES Medellín); Edwin Chapeta Parada, Andrés Minidiola Rochel, Richard Granados Chaparro (Hospital San Vicente de Arauca - Arauca); Francisco Molina, Madelyne Aristizábal, Marcela Cortés (Clínica Universitaria Bolivariana - Medellín); Erick de Jesús Valencia, Cristian Eduardo Moreno Niño, Julián David Paniagua (Clínica SaludCoop - Medellín); Daniel Molano Franco, José Rojas Gambasica, Albert Valencia (Clínica Universitaria Colombia Colsanitas - Bogotá); Guillermo Ortiz Ruíz, Manuel Garay Fernández, Antonio Lara Garkcia, Rafael A. Meza Matallana, Mario A. Mercado Díaz (Hospital Santa Clara - Bogotá); Juan Arias, Carlos Carvajal (Hospital Pablo Tobón Uribe - Medellín); Felipe Reyes, Carlos Bustamante, Ricardo Buitrago (Fundación Clínica Shaio Bogotá); Juan C Arango (Instituto Neurológico de Colombia - Medellín); Erick de Jesús Valencia, Cristina E Moreno, Julián D Paniagua (Clínica SaludCoop - Medellín); Rubén D Camargo Rubio, José Jaraba, Ricardo Romero (Clínica General del Norte - Barranquilla); Carlos A. Pacheco Melo (Clínica El Rosario Sede Tesoro - Medellín); Abraham Ali Munive, Ángela Hernández, Fabio Varón Vega (Fundación Cardioinfantil - Bogotá); José A. Rojas Suárez, Jennifer González, Laura Loaiza (Gestión Salud SAS Cartagena); Alejandro Rey (Clínica Centro - Barranquilla); Mario Gómez Duque, Mario Villabón González, Daniel Molano (Hospital San José Grupo Investigación CIMCA - Bogotá); César Enciso Olivera, Ronald Medina Lombo (Hospital Infantil Universitario de San José - Bogotá); Edwin G. Chapeta Parada, Andrés Mindiola, Andrés Corchuelo (Hospital
San Vicente - Arauca); Luis A. Muñoz, Miguel Coral Pabón (Clínica Fundadores - Bogotá); Costa Rica: Juan Villalobos Vindas, María C. Peláez Gil, Sergio Calderón Bejarano (Caja Costarricense del Seguro Social, Hospital México - San José); Ecuador: Diego Barahona Pinto, Leonardo Pazmiño Narvaéz, Nelson Remache

Vargas, Mijayl Jativa (Hospital de los Valles - Quito); Fernando Paredes Oña, Cristian Peláez, Pedro Torres, (Hospital San Francisco - Quito); Diego Morocho Tutillo, María Fernanda García, Edgar Espinosa (Hospital Eugenio Espejo - Quito); Estuardo Salgado Yepez, Diego Morocho, Santiago Parraga (Clínica La Merced - Quito); Freddy Morales Álava, Blanchy Macías Romero, Juan F. Morales Moreira (Hospital Oncológico Dr. Julio Villacreses Colmont - Portoviejo); Gleinner J. Cañarte Bermúdez, Verónica Llerena, José Mora (Hospital IESS - Portoviejo); Luis Herrera, Ana M. Díaz, Roberto González (Hospital Instituto Ecuatoriano Seguridad Social Ibarra - Ibarra); José Vergara Centeno, Luis González Zambrano, Gonzalo Sánchez Sánchez (Hospital Luis Vernaza - Guayaquil); Fausto Guerrero, Guillermo Falconi (Hospital Carlos Andrade Marín - Quito); Mijail Jativa, Tatiana Moreno, Patricio Acosta (Hospital San Francisco - Quito); Virginia Intriago Cedeño, Luís Bermudez Zambrano (Hospital Verdi Cevallos Baldo - Portoviejo): Spain: Alejandro Rodríguez, María Bodí, Sandra Trefler, Mónica Magret, Judith Marín, Laura Claverias, Candela Solé (Hospital Joan XXIII - Tarragona) Ignacio Martín-Loeches, Emili Díaz, Jordi Vallés, Antonio Artigas, Craig Dunlop, Eva Torrents (Hospital Parc Taulí - Sabadell); Francisco Álvarez Lerma, María P Gracia Amilla, Marta Bassas (Hospital del Mar Barcelona); Pedro Cobos Castellano (Hospital Punta de Europa - Algeciras); Sergio Ruíz-Santana; Catalina Sánchez Ramírez; Liliana Caipe Balcázar; Silvia Hípola Escalada (Hospital Dr. Negrín - Canarias); Adrià Albis, Estel Güell, Jordi Almirall, Mari de la Torre (Hospital de Mataró); Miguel Angel Blasco Navalpotro, Mónica Fuentes Ponte, Laura Sanz Sanz (Hospital Severo Ochoa- Madrid); Patricia Albert del Cruz, Esther García Sánchez, Manuel Cruz Tejedor (Hospital Universitario del Sureste - Madrid); Xavier Nuvials Casals; Mercedes Palomar, Montserrat Valverdú Vidal, Begoña Balsera Garrido (Hospital Arnau de Vilanova- Lleida); María Del Valle Ortiz, Esther Martínez Barrio, Sergio Ossa Echeverri (Hospital de Burgos); Susana Sancho Chinesta, Rafael Zaragoza, Nerea Buceta, Mar Criado (Hospital Dr. Peset - Valencia); Joaquim Amador Amerigo, Ma Teresa Jurado Castro, Alfons Arizmendi Demay (Hospital de Terrassa); Abelardo García de Lorenzo y Mateos, María Antonia Arce Mendiburo, Eva Perales Ferrera (Hospital La Paz - Madrid); Ignacio Javier Catalán Gómez, Claudia Domínguez Curell, Silvia Cano Hernández (Hospital de Manresa - Manresa); Nieves Cruza Leganes, Ruth Corpas Fernández, María Herreros Gonzalo (Hospital Nuestra Señora del Prado, Talavera de la Reina - Toledo); Carmen J. Fernández González, María José Castro Orjales, Francisco Javier Rodríguez Fariñas (Complejo Hospitalario de Ferrol - Ferrol), Paula Ramírez Galleymore, José Ricardo Gimeno Costa, Mónica Gordón Sahuquillo Cristina López Ferraz (Hospital La Fe - Valencia); Pablo Vidal Cortés, Víctor J. López Ciudad, Paula

Fernández Ugidos (Complejo Hospitalario de Ourense - Ourense); Leonardo Lorente Ramos, Oswaldo González Hernández (Hospital U de Canarias Tenerife), Lourdes cordero lorenzana, Abel Vázquez González, María Matachana Martínez (Complejo Hospitalario A Coruña - A Coruña); José María Bonell Goytisolo, Ignacio Jara Zozaya, Isabel Ceniceros Rozalén (Hospital Quirón Palmaplanas - Palma de Mallorca); Jordi Solé Violán, José María Ferrer Agüero, Ana Marrero (Hospital Dr. Negrín - Canarias); María del Mar Martín Velasco, José Sánchez Godoy (Hospital de la Candelaria - Tenerife ); Pedro Ma Olaechea Astigarraga, Celia Sañudo Ugarte, Eneritz Gamboa Azpiazu (Hospital de Galdakao-Usansolo - Vizcaya); José Blanquer, Gerardo Aguilar, Carlos Delgado, F. Javier Belda (Hospital Clínico - Valencia); Emma Muñoz Quiñones, Yolanda del Castillo Durán, Raquel Alcega Estivill (Hospital Sant Pau i Santa Tecla - Tarragona); Javier Blanco Pérez, Rebeca Álvarez Lata, Vanesa María Camba Dopazo (Hospital Lucus Augusti (HULA) - Lugo); Luis Cabré Pericas, Milagros Calizaya, Eugenia Portillo, David Manzanedo (Hospital de Barcelona-SCIAS); Vicent López Camps, Miguel Ángel García García, David Arizo León, Manuel Palomo Navarro (Hospital de Sagunto - Valencia); María Pilar Posada González, María José Rodríguez Fernández, Juan Ignacio Chico Carballas (Hospital Xeral - Vigo); Vanesa Gómez Casal, Sabela Vara Adrio, Guillermo Lago Preciado (Hospital Xeral Cies - Vigo) Antonia Socias Mir, Llorenç Socias Crespí, María Romero Carratalá (Hospital Son Llatzer Palma de Mallorca); Juan Carlos Ballesteros Herráez, Pilar Vázquez Paredes, Laura Sánchez Montori (Hospital Universitario Salamanca); Antonio L. Ruíz 
Aguilar, Alejandra Morón Giménez, Agustín Carlos Nebra Puertas, Marta Gurpegui Puente, Pilar Araujo Aguilar, Fernando Barra Quilez (Hospital Universitario Miguel Servet - Zaragoza); Mercedes Nieto, José M. Campos, Francisco J Romero, Mónica Requesens, Carmen Sánchez, Beatriz Busto (Hospital Clínico San Carlos - Madrid); Ma Concepción Valdovinos Mahave, José Ma Montón Dito, Ma Jesús Santed Andrés (Hospital Obispo Polanco Teruel); Alfredo Marcos Gutiérrez, Ana Carolina Caballero Zirena (Hospital Virgen de la Concha - Zamora); Belén Jiménez, Pilar Luque, Raquel Bustamante, Carlos M. Sánchez Polo (Hospital Clínico - Zaragoza); Rafael Carrasco, Ainhoa Menéndez, Antonio Sangio (Hospital del Vinalopó - Elche); Adoración Alcalá López, Carmen Abad Terrado, Diana Martínez (Hospital General Universitario Elche); Carlos Castillo Arenal, Juan Castedo González (Hospital Taxorritxu - Vitoria); Concha Moragues, Rubén González (Hospital Universitario La Plana - Vila-real Castellón); Noemí M. Gil Pérez, Isabel M. Peña Luna, David F. López Hormiga (Hospital de Mérida - Mérida); Francisco José Fuentes Morillas, Pablo Nieto Sánchez, José Alfonso Rubio Mateo-Sidrón (Hospital U. Infanta Cristina - Badajoz); José Manuel Allegue Gallego, Roberto Jiménez Sánchez, Sergio Rebollo, Roberto Jiménez Sánchez (Hospital Santa Lucía - Cartagena); Esperanza Molero Silvero, Alberto González Estebanez, Manuel Pérez Ale (HCD Gómez Ulla - Madrid); Mauricio Valencia, Sonia Piug (Hospital Clinic - Barcelona); Ana Abella Álvarez, Cecilia Hermosa Gelbard, Inés Torrejón Pérez (Hospital Universitario del Henares - Coslada); Ramón Fernández-Cid, Otilia Pons (Hospital Mateu Orfila - Mahón); Hasania Abdel-Hadi Álvarez, Alfonso Ambros Checa (Hospital General de Ciudad real - Ciudad real); Bernardo gil, Lola del Baño Aledo (Hospital Morales Meseguer - Murcia); Inés Navarrete Sánchez (Hospital Virgen de las Nieves - Granada); Pedro Rascado Sedes, Caridad Martín López (Hospital de Conxo - Santiago de Compostela); Antonio Rivera Fernández, Ana L. Balán Mariño, Marta Martín Cuadrado (Hospital San Agustín - Aviles); Noemí Llamas Fernández, José H. de Gea García, Iván Keituqwa Yáñez (Hospital Universitario Rafael Méndez de Lorca Murcia); César Bocanegra Abarca, Carlos Ramírez González, Chiara Caciano Reategui (Hospital Universitario Gregorio Marañón - Madrid); Fernando García López (Hospital General de Albacete - Albacete); Antonio Albaya (Hospital de Guadalajara - Guadalajara); Carmen Fernández (Hospital Marcide - Ferrol); Antonio Martínez Pellus (Hospital Virgen de la Arrixaca - Murcia); Belén Jiménez (Hospital Lozano Blesa - Zaragoza); Rafael Sierra (Hospital Puerta del Mar - Cádiz); César Aragón (Hospital de Málaga - Málaga); Iratxe Seijas Betolaza (Hospital de Barakaldo - Barakaldo); Felipe Bobillo (Hospital Clínico - Valladolid); Paula Vera Artacoz (Hospital Sant Pau - Barcelona); Ana C. Caballero Zirena (Hospital Virgen de la Concha - Zamora); Teresa Recio Gómez (Hospital San Pedro Alcántara - Cáceres); Ricard Jordá Marcos (Clínica Rotger - Palma de Mallorca); César Palazón, África López, Bernardo Gil Rueda (Hospital Universitario Reina Sofía - Murcia); Cancha Moragues Ribes (Hospital La Plana - Vila Real de Castellón); José M, Bonell Goytisolo (USP Clínica Palma Planas - Palma de Mallorca); César Pérez Calvo (Hospital Fundación Jiménez Díaz Capio - Madrid); Luis Tamayo (Hospital Universitario Río Hortega - Valladolid); Laura Macaya Redin, Jorge Echevarria Guibo, Lourdes Fisac Cuadrado (Complejo Hospitalario de Navarra UCIB - Pamplona); Sara Benito, María Pilar Anguiano, Joaquin lobo (Complejo Hospitalari Navarra UCI A - Pamplona); María Victoria de la Torre Prados, Carmen Trujillano Fernández, Jonathan Pérez Vacas (Hospital Universitario Virgen de la Victoria - Málaga); Mónica Zamora Elson, Tomas Mallor Bonet, Lorenzo Labarta Monzón (Hospital San Jorge - Huesca); Enrique Alemparte Pardavila, José Luís Martínez Melgar, Ana Ortega Montes (Complejo Hospitalario de Pontevedra - Pontevedra); Sandra Rodríguez Bolaños, José Luis Bellot Iglesias, Francisco González Martínez (Hospital General Básico de Baza - Granada); France: Nicolas Weiss (Hôpital Pitié-Salpêtrière - Paris); Benoit Voisin (Centre Hospitalier de Bethune -Bethune); Nicolas Van Grundenbeerck (Centre Hospitalier de Lens - Lens); Laurent Robriquet (CHRU de Lille - Lille); Philippe Seguin (Hôpital Pontchaillou Rennes); Philippe Cabaret (Hôpital St. Phillibert - Lille); Guillaume Brunin (CH Duchêne - Boulogne Sur Mer); Frédéric Brun (Hôspital Pierre Oudot - Bourgoin -Jallieu); Caroline Blazejewski (CHRU de Lille - Lille); Pascale Beuret (CH de Roanne - Roanne); Sébastien Béaque (Hôpital de Dunckerque - Dunckerque); Elie Azoulay (Hôpital St. Louis - Paris); Laurent Argaud (Hôpital Edouard Herriot - Lyon); Jean-Paul Mira, Julián Charpentier (Hôpital Cochin Paris); Martine Nyunga ( $\mathrm{CH}$ de Roubaix - Roubaix); Pablo Massanet ( $\mathrm{CH}$ de Montpellier - Montpellier); Florent Dewavrin; Isabelle Alves (CH de Valenciennes Valenciennes); Sébastien Préau (CHRU de Lille - Lille); Erika Parmentier-Decruca (CHRU de Lille - Lille); Saad Nseir (CHRU de Lille - Lille); Miguel Montanes Romain (Hôpital Beanjan APHP - Clichy); Stéphane Mérat (Hôpital d'Instruction des Armés
Begin - Saint Mandé); Bruno Mégarbane (Hôpital Lariboisiere - Paris); Olivier Leroy (Hôpital Chatiliez - Tourcoing); Bernard Just (CH de Charleville-Mezieres Charleville-Mezieres); Claude Guérin (Hôpital Croix-Rousse - Lyon); Christophe Girault (Hôpital Charles Nicolle - CHU de Rouen - Rouen); Jean-Yves Fagon (Hôpital Européen Georges-Pompidou -Paris ); Joel Cousson (Hôpital Robert Debré - Reims); Marc Clavel (CHU Dupuytren - Limoges); Benoit Misset (Groupe Hospitalier Paris St. Joseph - Paris Guatemala: Jorge L. Ranero Meneses, Rudy M. López (Instituto Guatemalteco de Seguridad Social - Guatemala); Luis D. González Patzan, César Cortez (Centro Médico Militar - Guatemala); Mexico: Luis D. Sánchez Velázquez, Marco A. Díaz Riveros, Araceli Muñoz Carrillo (Hospital General de México - México DF); Peru: Iván Ramos Palomino, Percy Cancina Prosopio (Clínica San Gabriel - Lima); Martín Oyanguren Miranda (Hospital Nacional E. Rebagliati Martins - Lima ); Luis Castillo Bravo, Pedro Fajardo Luna, Indira Oyanguren Miranda (Instituto de Enfermedades Neoplásicas - Lima); Indira Oyanguren Miranda, Luis Castillo Bravo, Vladimir M. Trelles (Clínica Angloamericana - Lima); Manuel Mayorga, Luis Martín Santivañez, Myriam Yaringano (Hospital Central de la FAP - Lima); Juan Salas (Hospital Regional Trujillo - Trujillo); Manuel Jesús Mayorga Espichan, Myriam Yaringano, Luis Martín Santivañez Monge, Christian Manuel Rivera Heredia (Hospital Central de la Fuerza Aérea del Perú - Lima); Portugal: Rui Araújo, Ernestina Gomes, Elena Molinos (Hospital Pedro Hispano - Matosinhos); Estâvão Lafuente (Hospital Vale Sousa - Penafiel); Celeste Dias, José Artur Paiva, António Sarmento, Maria Santos (Hospital S. João - Porto); Paula Castelões, Ana Josefina (CHVNG - Gaia); Aurora Cadeco (Hospital Viana Castelo - Viana do Castelo); Francisco Esteves (CHTMAD - Vila Real); Nuno Catorze (Centro Hospitalar Medio tejo - Abrantes); Paulo Freitas, Isabel Serra (HFF - Amadora); Pedro Póvoa, Carolina Paulino (HSFX - Lisboa); José Andrade Gomes (Hospital Luz - Lisboa); Luis Bagulho, (CHLC - Lisboa); Carlos Candeias, Luís Coelho, Raquel Marques (CHLN - Lisboa); Antero Fernandes (Hospital Gracia d'Orta - Almada); Paulo André (Hospital Barreiro - Barreiro); José Vaz, António Mendes (Hospital Beja Beja); Fernando Pádua (Hospital Portalegre - Portalegre); José Júlio Nóbrega (CHF - Funchal). USA: Marcos I. Restrepo, Antonio Anzueto (UTHSCSAVSTVHCSALM - San Antonio); Uruguay: Alberto Deicas, Mario Torales, Fabio Grill (CASMU Montevideo); Mario Jesús Silva Castilla, María F. Alonso Silva, Jorge Modemel Ingold; Gino Limongi, Darwin Tejera, Rodolfo González (Asociación Española Primera en Socorros Mutuos - Montevideo); Venezuela: Flor Giannina Balbo Martínez, Selene M Espina Pacheco, Rosa D’Oliveira Tavares (Hospital Dr. Patrocinio Peñuela Ruíz, San Cristóbal - Tachira); Norma Ruíz, Néstor Brito, Yrene Vázquez (Hospital Militar Dr. Carlos Arvelos - Caracas); Stevens Salva (Hospital de Clínicas Caracas); Francys Moreno (Hospital Central Universitario - San Cristóbal).

\section{Author details}

${ }^{1}$ Hospital Joan XXIII Critical Care Department/IISPV/URV/CIBERES, Mallafre Guasch 4, 43007 Tarragona, Spain. ${ }^{2}$ Polyvalent Intensive Care Unit, São Francisco Xavier Hospital, Estrada do Forte do Alto do Duque, 1495-005 Lisboa, Portugal. ${ }^{3}$ Pôle de Réanimation, CHU de Lille, 2, avenue Oscar Lambret, 59037 Lille Cedex, France. ${ }^{4}$ Institute for Research and Education Postgraduate Program, Instituto Nacional de Câncer Praça Cruz Vermelha, 23 - Centro, 20230-130 Rio de Janeiro, Brazil. ${ }^{5}$ Hospital Municipal de Chivilcoy, Av. Hijas de San José 31, 6620 Chivilcoy, Buenos Aires, Argentina. ${ }^{6}$ Critical Care Centre, Corporació Sanitària I Universitaria Parc Taulí, Hospital De Sabadell Institut Universitari UAB, Ciber Enfermedades Respiratorias, Parc Taulí, 108208 Sabadell, Barcelona, Spain.

Received: 5 August 2013 Accepted: 24 January 2014 Published: 12 February 2014

\section{References}

1. Melsen WG, Rovers MM, Groenwold RH, Bergmans DC, Camus C, Bauer TT, Hanisch EW, Klarin B, Koeman M, Krueger WA, Lacherade J-C, Lorente L, Memish ZA, Morrow LE, Nardi G, van Nieuwenhoven CA, O'Keefe GE, Nakos G, Scannapieco FA, Seguin P, Staudinger T, Topeli A, Ferrer M, Bonten MJ: Attributable mortality of ventilator-associated pneumonia: a meta-analysis of individual patient data from randomised prevention studies. Lancet Infect Dis 2013, 13:665-671.

2. Melsen WG, Rovers MM, Koeman M, Bonten MJ: Estimating the attributable mortality of ventilator-associated pneumonia from randomized prevention studies. Crit Care Med 2011, 39:2736-2742.

3. Martin-Loeches I, Pobo A: What is new in ventilator-associated tracheobronchitis? Clin Pulm Med 2010, 17:117-121. 
4. Garner JS, Jarvis WR, Emori TG, Horan TC, Hughes JM: CDC definitions for nosocomial infections, 1988. Am J Infect Control 1988, 16:128-140.

5. Malacarne $P$, Langer M, Nascimben E, Moro ML, Giudici D, Lampati L, Bertolini G: Building a continuous multicenter infection surveillance system in the intensive care unit: findings from the initial data set of 9,493 patients from 71 Italian intensive care units. Crit Care Med 2008, 36:1105-1113

6. Torres A, Ewig S, Lode H, Carlet J: Defining, treating and preventing hospital acquired pneumonia: European perspective. Intensive Care Med 2009, 35:9-29.

7. Martin-Loeches I, Nseir S, Valles J, Artigas A: From ventilator-associated tracheobronchitis to ventilator-associated pneumonia. Reanimation 2013, 22:231-237.

8. Craven DE: Ventilator-associated tracheobronchitis (VAT): questions, answers, and a new paradigm? Crit Care 2008, 12:157.

9. Grgurich PE, Hudcova J, Lei Y, Sarwar A, Craven DE: Diagnosis of ventilator-associated pneumonia: controversies and working toward a gold standard. Curr Opin Infect Dis 2013, 26:140-150.

10. Mandell LA, Wunderink RG, Anzueto A, Bartlett JG, Campbell GD, Dean NC, Dowell SF, File TM Jr, Musher DM, Niederman MS, Torres A, Whitney CG, Infectious Diseases Society of America; American Thoracic Society: Infectious Diseases Society of America/American Thoracic Society consensus guidelines on the management of community-acquired pneumonia in adults. Clin Infect Dis 2007, 44:S27-S72.

11. Self WH, Courtney DM, McNaughton CD, Wunderink RG, Kline JA: High discordance of chest x-ray and computed tomography for detection of pulmonary opacities in ED patients: implications for diagnosing pneumonia. Am J Emerg Med 2013, 31:401-405.

12. Craven DE, Lei $Y$, Ruthazer R, Sarwar A, Hudcova J: Incidence and outcomes of ventilator-associated tracheobronchitis and pneumonia. Am J Med 2013, 126:542-549.

13. Palmer LB, Smaldone GC, Chen JJ, Baram D, Duan T, Monteforte M, Varela M, Tempone AK, O'Riordan T, Daroowalla F, Richman P: Aerosolized antibiotics and ventilator-associated tracheobronchitis in the intensive care unit. Crit Care Med 2008-2013, 2008:36.

14. Nseir S, Favory R, Jozefowicz E, Decamps F, Dewavrin F, Brunin G, Di Pompeo C, Mathieu D, Durocher A: Antimicrobial treatment for ventilator-associated tracheobronchitis: a randomized, controlled, multicenter study. Crit Care 2008, 12:R62.

doi:10.1186/cc13725

Cite this article as: Rodríguez et al:: Incidence and diagnosis of ventilator-associated tracheobronchitis in the intensive care unit: an international online survey. Critical Care 2014 18:R32.

\section{Submit your next manuscript to BioMed Central and take full advantage of:}

- Convenient online submission

- Thorough peer review

- No space constraints or color figure charges

- Immediate publication on acceptance

- Inclusion in PubMed, CAS, Scopus and Google Scholar

- Research which is freely available for redistribution

Submit your manuscript at www.biomedcentral.com/submit
C Biomed Central 